All issues of this journal are alternatively stored and archived by: the National Library of Thailand, Russian E-library and Index Copernicus library of journals, Poland

\title{
FINANCIAL ATTITUDES AND SUBJECTIVE NORMS INFLUENCING RETIREMENT PLANNING
}

\author{
Narit Kerdvimaluang \\ Jantima Banjongprasert
}

Silpakorn University, International College (SUIC), Bangkok, Thailand

Retirement counselors, financial planning specialists, and financial advisors often point out that attitudes and subjective norms are two highly important factors for saving intentions and retirement planning. The objective of this research is to investigate the effects of attitudes and subjective norms on saving plan intentions among the employees working in Thailand. This research has been conducted using the survey data on 400 employees (300 Thais and 100 foreigners) now working in Thailand. The key data analysis method has been Structural Equation Modeling (SEM) AMOS. The findings indicate that financial attitude has a positive effect on the saving plan intention, and subjective norms also have a positive effect on the saving plan intention. Therefore, employees should focus significantly on attitudes and subjective norms while creating their saving plans in the context of financial retirement planning. The study makes a scientific contribution in the form of s comprehensive model which is explaining investors' behavior in part of financial planning for retirement.

Keywords: financial attitudes; subjective norms; social influence; savings plan; saving intentions; saving behavior

\section{Introduction}

Population around the world has been declining, and this issue is already creating a huge impact on economic development of many countries (OECD, 2015).
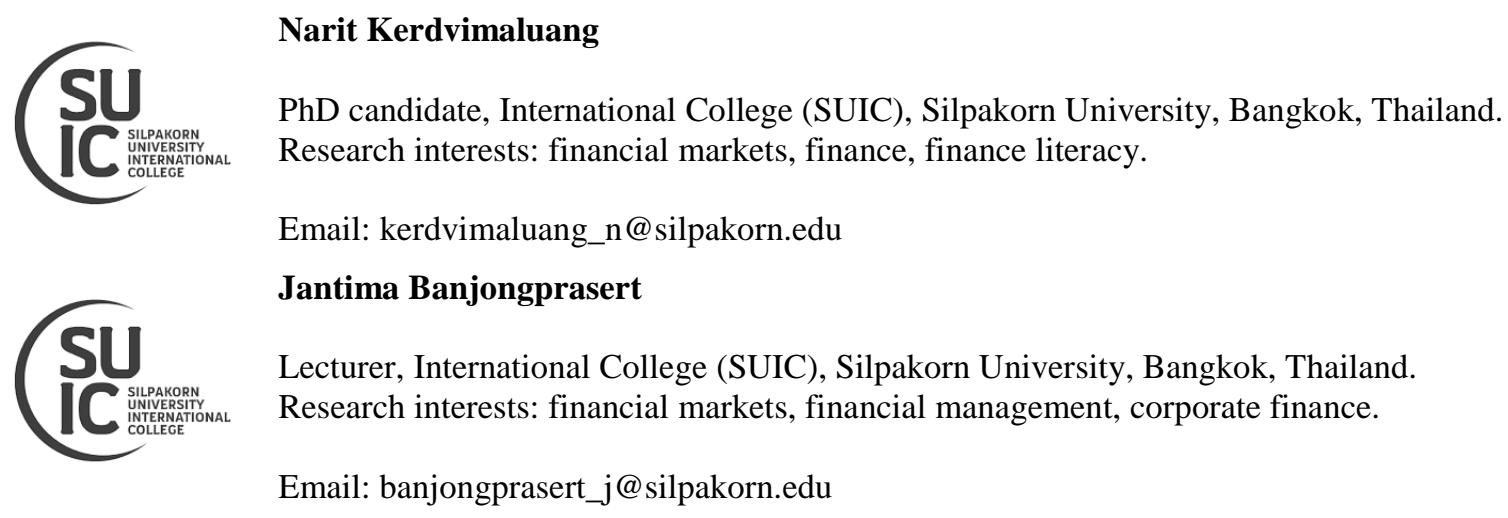


\section{FINANCIAL ATTITUDES AND}

Carbonaro et al. (2018) explained that demographic structural changes tend to have major negative impacts on the aggregate productivity growth. Population decline is resulting in an aging society, and this, in turn, has caused the financial imbalance problem in many countries, which is one of the key megatrends affecting the world economy these days.

The Organization for Economic Co-operation and Development (OECD) back in 2015 showed that lower government pension funds would be one of the main financial problems for the future elders. Therefore, retirees cannot rely on social security funds alone. Indeed, they need to consider voluntary pension plans that would additionally support them during the retirement period.

With undersavings, people would face poverty during the retirement period while having higher demand for healthcare services, social security, elder care, et al. Huhmann \& McQuitty (2009) believed that some workers saved insufficient retirement funding with higher expenses needed for the elderly stage.

The decreasing birth rate, lower death rates, and longer life expectancy are other, related concerns provoking public debate (Grace et al., 2010). Lusardi \& Mitchell (2011) pointed out that the majority of people in many areas failed to save and invest their money on the retirement funding or even failed to plan for as little as five or ten years ahead.

Having such inadequate savings, people are not able to survive on small amounts of government pensions only, thus, they could not enjoy their living on the retirement (Crawford \& O'Dea, 2020).

At the same time, people are totally different in their needs, so they need to be concerned about own investment assets and saving money on their own retirement plans. Everyone is also different in terms of occupation, earning income volume, tax incentives, benefits gained from retirement assets, which leads to differences in retirement financial planning. After a long working period of time, workers should be able to enjoy their retirement period, having proper amount of saving and/or suitable assets for generating adequate money income.

Some countries tend to force workers to enroll automatically into a retirement fund and thus automatically receive some benefits from investment planning.

However, such automatic programs could lead to people paying less attention to such investments, thus, they will tend to pay only small amounts of contribution as it is required by law (Pereira \& Afonso, 2020). The minimum contribution amount on the retirement financial planning could end with improper funding and eventually — no-income lives in the longer period of time.

When there is little or no attention to financial planning among the people, workers tend to make numerous mistakes in their retirement financial planning, like wrong retirement asset choices, paying no attention to the contribution amount, and having no financial knowledge to make suitable decisions on this very important issue (Sandbrook \& RaviBurslem, 2019).

Dauda et al. (2019) showed that financial attitudes and subjective norms tend to have a significant positive impact to the retirement financial savings intention. Attitude towards retirement financial planning means the positive or negative workers' perspective towards retirement planning. Subjective norm is the employees' perception of the surrounding people's opinions, approving or disapproving the retirement financial planning. 


\section{Literature Review}

\section{Financial attitude to behavior}

Financial attitude factors related to retirement planning could increase the consumer saving behavior. Based on the results of the previous studies on this topic, there are four components of the retirement financial planning attitude to behavior: parental financial behavior; future time perspective; propensity to plan; and goal clarity.

First, Parental Financial Behavior refers to the role of parents in developing children's skills and financial ability that could affect children's future retirement financial planning behavior (Kimiyagahlam et al., 2019).

The money management behavior of youths tends to be influenced by parents' financial behavior (Webley \& Nyhus, 2006; Jebarajakirthy \& Lobo, 2015). Moreover, Kimiyaghalam et al. (2019) revealed that parents significantly influence the financial management behavior of their children. Thus, this research argues that parents with healthy money management behavior affect the children's smart and well-managed financial attitudes.

Next, Future Time Perspective is the psychological variable of the financial planning attitude referring to households looking for future rather than past and present situations (Howlett et al., 2008). The future time perspective affects, inter alia, the individuals' attitudes concerning own financial planning behavior (Rabinovich et al., 2010).

Kimiyagahlam et al. (2019) explained that propensity to plan is the human attitude responsible for controlling conscious intentions and planning. This planning skills could generate the positive effect on the retirement financial planning.

Stawski et al. (2007) believed that defined long-term values are offering a strong direction, the sense of coherence, and the meaning to people. Neukam \& Hershey (2003) explained that financial goals' clarity is significantly positively correlated with people's saving contributions. Goals' clarity provides higher level of personal effectiveness and life satisfaction that, in turn, create more active patterns in retirement planning behavior.

In conclusion, all of these four variables help to increase the saving plan intentions that help with retirement planning and saving behavior. Based on the existing literature, we introduce the following hypothesis:

H.1 Saving attitude has a positive influence on the saving plan intention.

\section{Subjective norm to behavior}

Subjective norm is one of the concepts belonging to the Theory of Planned Behavior stating that social and environment's pressures could affect individuals' behavior and intentions (Ajzen, 1991). Subjective norm can be defined as the individuals' perception of a potential reference group that can approve or disapprove a specific behavior.

Dauda et al. (2019) explained that subjective norms or perceived social influence from families, friends, coworkers, and bosses may be leading all workers to engage in the retirement planning program. The possibility of the direct effect of a subjective norm on behavior might change over time.

Griffin et al. (2012) pointed out that subjective norms have a significant correlation with the retirement planning. The more other people are involved in the retirement planning programs, the greater would be the individual level of retirement planning involvement. 


\section{FINANCIAL ATTITUDES AND}

These can be influences from family, peers, colleagues, and bosses, all of them could lead to better preparation for financial retirement planning.

Dauda et al. (2019) argued that subjective norms have a positive correlation with the retirement planning and saving intentions. Some of the recent studies assume that the more employees' referent groups (families, friends, colleagues, and bosses) demonstrate the retirement savings intentions, the higher would be the workers' confidence regarding own engagement in retirement saving planning.

H.2 Subjective norms have a positive influence on the saving plan intentions.

\section{Saving Plan Intention}

Topa \& Alcover (2015) explained the concept of the retirement saving plan intention as the retirement decision process concerning the financial retirement assets. Different levels of the retirement saving intentions can bring different outcomes. At some point of time, all the workers would eventually consider the possible pathways to exit the working life with some sort of retirement savings.

Depending on the workers' own attitude and the surrounding subjective norms, this might have a significant impact on the personal saving plan intentions. Ganesan et al. (2020) determined that the saving plan intention represents an individual's motivation in the sense of planning consciousness or decision-making in the context of a certain behavior. Saving plan intention is how people plan and try towards performing their own saving plan behavior.

\section{Research Methodology}

From the theory of planned behavior, two important factors for performing saving plan intentions and saving behavior are the attitude and the subjective norm. This research is operating a quantitative approach while collecting data through questionnaires.

The population of this study were Thai and international employees working in Thailand, 400 sample units in total, following (Krejcie \& Morgan, 1970). Cochran (1977) explained that the sample size for an unknown population portion $(\mathrm{p}=0.5)$ by using the formula $\mathrm{n}=\frac{\mathrm{Z}^{2}}{4 \mathrm{e}^{2}}$ at the confidence level of $95 \%$ and the 0.05 significance level $(\mathrm{Z}=1.96)$ as follows:

$$
\mathrm{n}=\frac{1.96^{2}}{4(0.05)^{2}}=384.16 \approx 384
$$

From this number, the 400-unit sample size fits perfectly for the analysis with a structural equation model (SEM) (Yuan \& Bentler, 2000; Savalei \& Bentler, 2005).

Questionnaires were distributed among Thai and international employees at many locations such as shopping malls, public areas, restaurants, and also various heavy-traffic areas. All questionnaires were distributed by the research assistants following the preestablished criteria:

a) only one member from each family could answer the questionnaire;

b) the surveyed employees' income must be higher than 20,000 Baht per month as this is the level of income at which tax incentive programs and the related financial planning for retirement come into picture.

There have been two parts in the research questionnaires. The first concerned workers' decision-making process, following Attitude, Subjective Norm, and Saving Plan Intention 
(the possible answers have been scaled from 1 to 5). The second part contained demographic information - Gender, Age, Nationality, Education Level, Occupation, etc.

Five-rating-scale questionnaire was used as the research instrument. The measurement has incorporated three constructs - Attitude, Subjective Norm, and Saving Plan Intentions. For Attitude, there have been four parts to identify it: Parents' Financial Behavior (PFB), Future Time Perspective (FTP), Propensity to Plan (PTP), and Goals' Clarity (GC). For Subjective Norm, the combination of four aspects has been covered: Perceived Social Influence from Family (PSIF), Perceived Social Influence from Friends (PSIP), Perceived Social Influence from Colleagues (PSIC), and Perceived Social Influence from Superiors/Bosses (PSIB).

Another part in this study concerned Saving Plan Intentions. Following (Tabachnick et al., 2007; Hooper et al., 2013), statistics has been used in this research for further data analysis using the Structural Equation Modeling (SEM) and its good-fitness indices. However, the modification indices have been first re-examined and somewhat modified to fit into the model (Knekta et al., 2019).

All questions were initially assessed using the Content validity index (CVI) technique to evaluate and judge the relevance of potential questions for the survey purposes. These research questions were reviewed by five experts specializing in business and financial saving behavior in terms of four different parameters - relevance, clarity, simplicity, and ambiguity. What concerns the reliability statistics, the Cronbach's Alpha for this research is 0.954, that is, excellent level. In part of factor analysis, KMO is 0.928 (more than 0.6) and Bartlett's Test sig. 0.000 (less than 0.05).

In addition, this research has normal distribution of data as skewness and kurtosis values in each construct have the values in the range of $(-3,3)$ for all of the components. Therefore, stemming from all of these data points, we can assume that this research data has normal distribution with the excellent values of Cronbach's Alpha, KMO, and Barlett's Test.

The Confirmatory Factor Analysis (CFA) was studied in first order, second order, and higher order on the structural model. The final model was adjusted and constructed from the initial for good-fit model criteria. The $\mathrm{X}^{2}$ to the degree of freedom ratio is 2.083 (less than 3 ), with the p-value $=0.066$ indicating moderate good fit, $\mathrm{GFI}=0.848$, $\mathrm{AGFI}=0.816$, and RMSEA $=0.049$ for the absolute fit index.

Also, the comparative fit index is a moderate good fit as well because of CFI $=0.928$, $\mathrm{NFI}=0.871$, and TLI $=0.916$. From the good fit index, it was accepted for further analysis to confirm the hypotheses using the structural model.

\section{Research Results}

\section{Personal information of the respondents}

The respondents' demographics are shown in the Tab. 1.

\section{Attitude, Subjective Norm, Saving Plan Intention, and Saving Behavior}

The mean of each dimension was high level attitude (4.06), subjective norm (3.60), and saving plan intention (4.06). Each component shows the standard deviation in attitude (0.48), subjective norm (0.68), and saving plan intentions (0.56).

There are four parts in shaping the attitude to retirement financial planning - parent financial behavior, future time perspective, propensity to plan, and goals' clarity. In terms of 
subjective norms, there are four groups of people affecting the financial planning behavior, they are perceived as social influence from family, from friends, colleagues, and perceived social influence from superiors/ bosses.

In terms of the saving plan intentions, workers have to be ready for the retirement financial planning that comes from two independent factors on their side - attitude and subjective norms.

Table 1 - Demographic characteristics of the sample (complied by co-authors)

\begin{tabular}{|c|c|c|}
\hline Profile & Frequency & $\%$ \\
\hline \multicolumn{3}{|c|}{ Gender } \\
\hline Male & 174 & 43.50 \\
\hline Female & 226 & 56.50 \\
\hline \multicolumn{3}{|c|}{ Age (years) } \\
\hline $20-29$ & 73 & 18.25 \\
\hline $30-39$ & 91 & 22.75 \\
\hline $40-49$ & 154 & 38.50 \\
\hline $50-59$ & 67 & 16.75 \\
\hline 60 above & 15 & 3.75 \\
\hline \multicolumn{3}{|c|}{ Nationality } \\
\hline Thai & 300 & 75.00 \\
\hline Non-Thai & 100 & 25.00 \\
\hline \multicolumn{3}{|c|}{ Marital Status } \\
\hline Single & 149 & 37.25 \\
\hline Married & 205 & 51.25 \\
\hline Divorced & 9 & 2.25 \\
\hline Cohabiting & 37 & 9.25 \\
\hline \multicolumn{3}{|c|}{ Education } \\
\hline No formal education & 13 & 3.25 \\
\hline High School & 65 & 16.25 \\
\hline Bachelor's degree & 203 & 50.75 \\
\hline Master's degree & 101 & 25.25 \\
\hline Doctorate/Ph.D. & 18 & 4.50 \\
\hline
\end{tabular}

Table 2 - Summary of standardized estimates, standard error, and critical value (complied by co-authors)

\begin{tabular}{|c|c|c|c|c|c|c|c|c|}
\hline Hypotheses & \multicolumn{3}{|c|}{ Items } & Standardized & S.E. & C.R. & $\mathrm{P}$ & Hypotheses \\
\hline H1 & ATT & (i) & SPI & 0.68 & 0.053 & 11.991 & **** & Accepted \\
\hline $\mathrm{H} 2$ & SJN & (b) & SPI & 0.27 & 0.031 & 6.236 & **** & Accepted \\
\hline
\end{tabular}

All the variables were accepted and the absolute value of t-test or C.R. is higher than 1.96 for all the tested hypotheses. Thus, all the hypotheses are accepted at the 0.001 
significance level. From the standardized estimate $(\beta)$, the standardized estimate of attitude has a positive effect on saving plan intentions with $(\beta=0.68)$, the standardized estimate of subjective norm on saving plan intention with $(\beta=0.27)$. Other details on the model could be seen in Fig. 1.

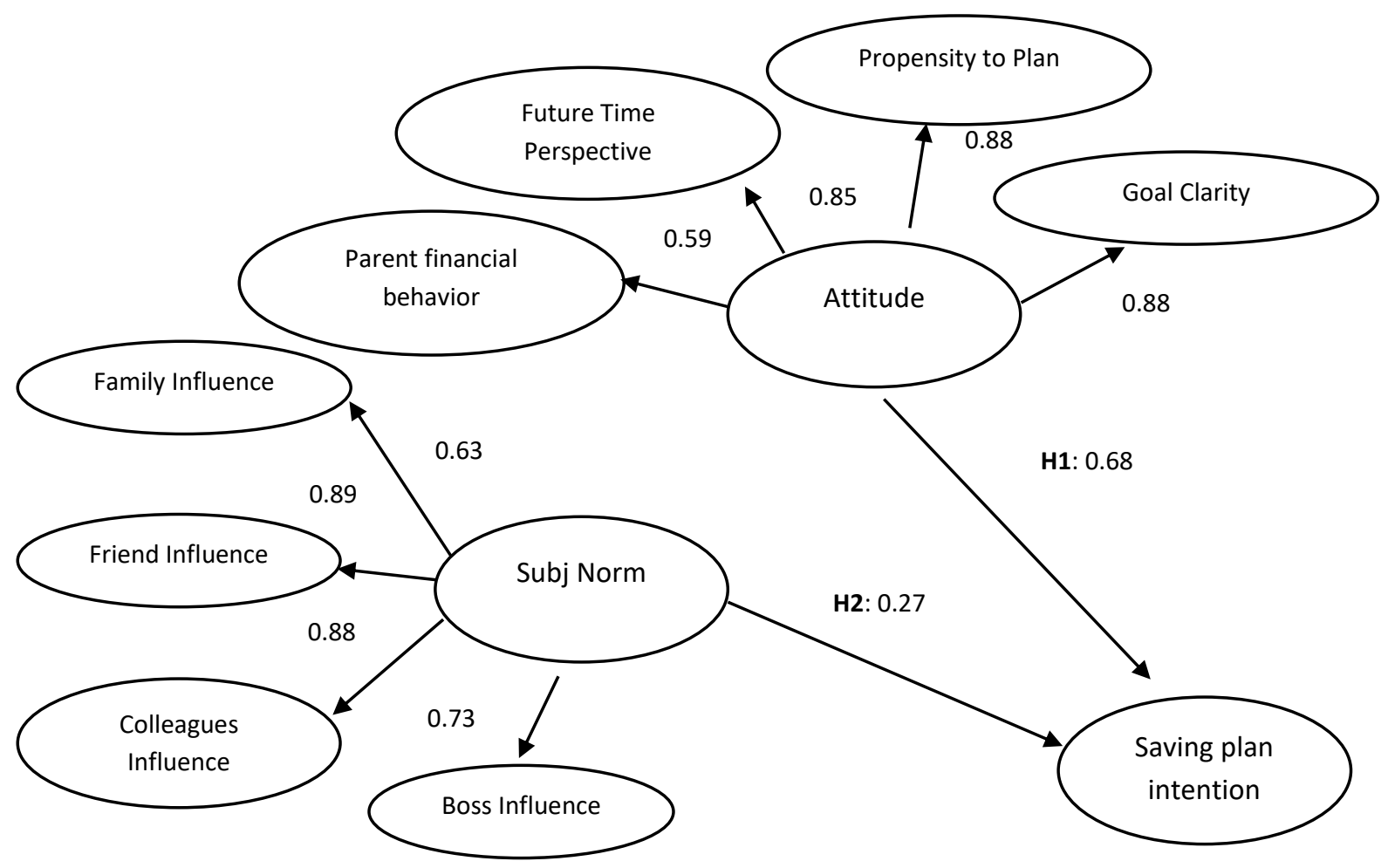

Figure 1 - The model of Attitude, Subjective Norm, and Saving Plan Intention (complied by co-authors)

\section{Discussion and Recommendation}

This paper presents and proves a positive relationship between the Attitude and the Saving Plan Intentions as well as between the Subjective Norm and the Saving Plan Intentions. In part of Attitude, this research has found that both Propensity to Plan and Goals' Clarity play an important role for the financial attitude for retirement planning, followed by Future Time Perspective, and Parents Financial Behavior.

In part of Subjective Norm, there are some influences coming from the outside parties and affecting the retirement plan intentions and saving behavior. More specifically, friends tend to play an important role through social influence on retirement planning and the related savings. After that, colleagues, bosses, and family respectively influence the workers' retirement planning. For both of these variables, this research results point out that workers usually discuss their retirement financial planning, less so with their immediate families, as compared to other social circles. Saving plan intention receives a positive effect from the Attitude and the Subjective Norm which is translated here into the positive correlation: the more attitude and subjective norm, the more saving plan intentions among the employees. Once employees have some sort of saving plan intentions, these intentions are significantly 


\section{FINANCIAL ATTITUDES AND}

leading them to the retirement saving behavior. Therefore, we have to encourage people with the saving plan intentions to transform these intentions into successful saving behavior and the actual financial retirement savings.

Concerning research implications here, there are two parts of them - those for employees and those for policy makers. For workers themselves, this research shows that people tend to be concerned about their financial goals' clarity, propensity to financial planning, and future time perspective. Moreover, workers rely on their parents' financial behavior less, even though parents' financial behavior is playing a very important role for their kids (Webley \& Nyhus, 2006; Jebarajakirthy \& Lobo, 2015) and is also related to smart and well-managed financial attitude of their kids (Kimiyaghalam et al., 2019). Thereby, parents should discuss more various financial issues with their children rather than revealing this financial issue directly.

This point of view is directly related with the Subjective Norm result: workers tend to discuss and receive the influence from outside the family member circle, more from friends, colleagues, and even bosses.

However, family influences on employees when it comes to financial planning is seriously less significant.

For policy makers: government authorities and companies' top management should educate people regarding their financial planning attitudes, retirement planning and the related savings. If workers have more alternative ideas regarding their potential retirement financial planning, they would have more saving plan intentions which would lead to a more saving behavior.

Attitudes and subjective norms are always effecting financial retirement planning, thus, every country should be able to reduce these potentially negative impacts on the aging, especially if those directly lead to the financial problems for the whole society. Developed and well positioned retirement financial saving behavior could lead people to having much higher standards of living after the retirement.

\section{Conclusion}

People in all the countries might suffer from the effects of improper living standards during the retirement period because they had not saved enough money for future spending in the non-income period. Therefore, all the working-age employees should focus more on their retirement attitude, such as, parents' financial behavior, future time perspective, propensity to plan and goals' clarity in retirement saving.

On the other side, perceived social influences from parents, friends, colleagues, and superiors could also impact the saving plan intentions and the financial retirement planning overall. Once the saving plan intention is created, employees could develop and adjust it further, until getting on the right retirement saving behavior and then implement it into the practical saving behavior.

For a successful retirement financial planning, such a saving behavior should start with employees' attitude and subjective norms as the key factors that all the companies and the government should support while the retirement financial plan is being accomplished. People with some extra savings for their retirement period would be able to not only survive but would also be much less of a burden on the society and the government. 


\section{References:}

Ajzen, I. (1991). The theory of planned behavior. Organizational behavior and human decision processes, 50(2), 179-211.

Carbonaro, G., Leanza, E., McCann, P. \& Medda, F. (2018). Demographic decline, population aging, and modern financial approaches to urban policy. International Regional Science Review, 41(2), 210-232.

Cochran, W. G. (1977). Sampling Techniques. Wiley.

Crawford, R. \& O'Dea, C. (2020). Household portfolios and financial preparedness for retirement. Quantitative Economics, 11(2), 637-670.

Dauda, S., Tolos, H. \& Ibrahim, Y. (2019). The direct predictors of retirement planning behavior: a study of Nigerian workers. Available online at: https://www.researchgate.net/publication/322308068_The_Direct_Predictors_of_Retirement_P lanning_Behavior_A_Study_of_Nigerian_Workers.

Ganesan, Y., Pitchay, A. B. A. \& Nasser, M. A. M. (2020). Does intention influence the financial literacy of depositors of Islamic banking? A case of Malaysia. International Journal of Social Economics, 47 (5), 675-690.

Grace, D., Weaven, S. \& Ross, M. (2010). Consumer retirement planning: An exploratory study of gender differences. Qualitative Market Research: An International Journal, 13(2), 147-188.

Griffin, B., Hesketh, B. \& Loh, V. (2012). The influence of subjective life expectancy on retirement transition and planning: a longitudinal study. Journal of Vocational Behavior, 81(2), 129-137.

Hooper, D., Coughlan, J. \& Mullen, M. R. (2013). The servicescape as an antecedent to service quality and behavioral intentions. Journal of services marketing, 27 (4).

Howlett, E., Kees, J. \& Kemp, E. (2008). The role of self-regulation, future orientation, and financial knowledge in long-term financial decisions. Journal of Consumer Affairs, 42(2), 223-242.

Huhmann, B. A. \& McQuitty, S. (2009). A model of consumer financial numeracy. International Journal of Bank Marketing, 27 (4), 270-293.

Jebarajakirthy, C. \& Lobo, A. (2015). A study investigating attitudinal perceptions of microcredit services and their relevant drivers in bottom of pyramid market segments. Journal of Retailing and Consumer Services, 23, 39-48.

Kimiyagahlam, F., Safari, M. \& Mansori, S. (2019). Influential behavioral factors on retirement planning behavior: The case of Malaysia. Journal of Financial Counseling and Planning, 30(2), 244-261.

Knekta, E., Runyon, C. \& Eddy, S. (2019). One size doesn't fit all: Using factor analysis to gather validity evidence when using surveys in your research. CBE - Life Sciences Education, 18(1), rm1.

Krejcie, R. V. \& Morgan, D. W. (1970). Determining sample size for research activities. Educational and psychological measurement, 30(3), 607-610.

Lusardi, A. \& Mitchell, O. S. (2011). Financial literacy around the world: an overview. Journal of pension economics \& finance, 10(4), 497-508. 


\section{FINANCIAL ATTITUDES AND}

Neukam, K. A. \& Hershey, D. A. (2003). Financial inhibition, financial activation, and saving for retirement. Financial Services Review, 12(1), 19.

OECD (2015). Ageing in Cities. Organization for Economic Cooperation and Development, Paris. Available online at: https://www.oecd.org/regional/ageing-in-cities-9789264231160-en.htm.

Pereira, A. G. \& Afonso, L. E. (2020). Automatic enrollment and employer match: an experiment with the choice of pension plans. Revista de Gestão.

Rabinovich, A., Morton, T. \& Postmes, T. (2010). Time perspective and attitude-behaviour consistency in future-oriented behaviours. British Journal of Social Psychology, 49(1), 69-89.

Sandbrook, W. \& Ravi-Burslem, R. (2019). Communicating NEST Pensions for 'New' DC Savers in the Kingdom. Available online at: https://openknowledge.worldbank.org/handle/10986/31652.

Savalei, V. \& Bentler, P. M. (2005). A statistically justified pairwise ML method for incomplete non normal data: A comparison with direct ML and pairwise ADF. Structural Equation Modeling, 12(2), 183-214.

Stawski, R. S., Hershey, D. A. \& Jacobs-Lawson, J. M. (2007). Goal clarity and financial planning activities as determinants of retirement savings contributions. The International Journal of Aging and Human Development, 64(1), 13-32.

Tabachnick, B. G., Fidell, L. S. \& Ullman, J. B. (2007). Using multivariate statistics, 5, 481-498.

Topa, G. \& Alcover, C. M. (2015). Psychosocial factors in retirement intentions and adjustment: a multi-sample study. Career Development International, 20 (4), 384-408.

Webley, P. \& Nyhus, E. K. (2006). Parents' influence on children's future orientation and saving. Journal of Economic Psychology, 27(1), 140-164.

Yuan, K. H. \& Bentler, P. M. (2000). Three likelihood-based methods for mean and covariance structure analysis with non-normal missing data. Sociological methodology, 30(1), 165-200.

Paper submitted

Paper accepted for publishing

Paper published online
14 November 2021

28 December 2021

31 January 2022 